\title{
POLÍTICAS PÚBLICAS DE INCENTIVO À INSERÇÃO DA AGRICULTURA FAMILIAR NA CADEIA PRODUTIVA DO BIODIESEL E SUA INTER-RELAÇÃO COM O DIREITO AO DESENVOLVIMENTO E A AGENDA 2030 DA ONU
}

Adriana Monte Pereira de Macedo Sampaio ${ }^{1}$

\begin{abstract}
Resumo
A relação entre as mudanças climáticas e catástrofes ambientais exige dos Estados políticas de desenvolvimento sustentável. O Programa Nacional de Produção e Uso do Biodiesel além de estabelecer a obrigatoriedade do percentual de biodiesel na composição do diesel comercializado, possui uma política de inclusão com incentivos a participação de famílias praticantes da agricultura familiar na cadeia produtiva do biodiesel e apresenta objetivos que se interrelacionam com os Objetivos da Agenda 2030 da ONU. Apesar da efetividade dos resultados alcançados, fatores econômicos como o alto preço do biodiesel vêm levando a modificações na política, desincentivando a produção de biodiesel no país.
\end{abstract}

Palavras-chave:biodiesel; desenvolvimento sustentável; agriculatura familiar; PNPB; Agenda 2030

\section{PUBLIC POLICIES TO ENCOURAGE FAMILY AGRICULTURE INTO THE BIODIESEL PRODUCTION AND ITS INTERRRELATION WITH THE RIGHT TO DEVELOPMENT AND THE UN AGENDA 2030.}

\begin{abstract}
The relationship between climate change and environmental disasters demands sustainable development policies. The Brazilian National Program for Production and Use of Biodiesel, in addition to establishing a mandatory percentage of biodiesel in the diesel sold, has an inclusion policy that incentives a participation of families in the biodiesel production chain and presents interrelated objectives with the goals of the UN 2030 Agenda. Despite the effectiveness of the results achieved, economic factors such the price of biodiesel have been leading to changes in the policy, discouraging the production of biodiesel in the country.
\end{abstract}

Keywords: biodiesel; sustainable development; family farmery; PNPB. UN 2030 Agenda

\section{INTRODUÇÃO}

O debate acerca das mudanças climáticas e a sua relação com catástrofes ambientais ocorridas no planeta tem sido o tema dos principais encontros entre os líderes dos mais diversos países no âmbito internacional, gerando uma crescente pressão sobre os Estados para a promoção de políticas públicas e estratégias que tornem possível o desenvolvimento de maneira sustentável. Entretanto, em que pese a necessidade de buscar manter a temperatura global em

\footnotetext{
${ }^{1}$ Mestranda em Direito - PPGD UFRN
} 
níveis aceitáveis para a própria sobrevivência da humanidade (IPCC, 2021), erradicar a pobreza também é um desafio diante das inúmeras crises humanitárias causadas pela pobreza e a fome.

Em 2015, os representantes dos 193 Estados-membros da ONU se reuniram e concluíram que a erradicação da pobreza em todas as suas formas e dimensões é o maior desafio global e um requisito indispensável para o desenvolvimento da humanidade, e foi criada a Agenda 2030, um plano de ação que possui 17 Objetivos do Desenvolvimento Sustentável, os ODS, e 196 metas para erradicar a pobreza e proteger o meio ambiente e o clima, e que os países adotam de acordo com as suas prioridades.

Os efeitos causados pelas alterações climáticas são mais sentidos nos países em desenvolvimento, os quais, historicamente, menos contribuíram para a sua causa. Entretanto, levando-se em consideração a tendência de que esses países passem a ser os maiores emissores, é importante que também realizem esforços para mitigar suas emissões, devendo encontrar meios de fazê-lo sem grandes impactos em seu crescimento econômico (DISSANAYAKE; MAHADEVAN; ASAFU-ADJAYE, 2020).

Um dos maiores fatores causadores de emissões é a utilização de combustíveis fósseis para a produção de energia. Na busca por uma energia que produza menos emissões, os biocombustíveis são uma opção que favorece, além do meio ambiente, a área econômica e social, pois pode desenvolver de regiões agrícolas e pobres, permitindo a inserção de tecnologias apropriadas de acordo com as características de cada região e, paralelamente, se uma forma sustentável, sem comprometer o desenvolvimento das gerações futuras.

A fim de incentivar a produção nacional, o Brasil elaborou políticas públicas como o Programa Nacional de Produção e Uso do Biodiesel (PNPB), um programa interministerial do Governo Federal que objetiva a implementação de forma sustentável, tanto técnica como econômica, da produção e uso do biodiesel, com enfoque na inclusão produtiva e no 
desenvolvimento rural sustentável, por meio da geração de emprego e renda, com a inserção da agricultura familiar na cadeia produtiva do biodiesel e oRenovaBio, Política Nacional de Biocombustíveis, instituída através da Lei 13.576/2017 e que tem por objetivo fomentar a produção de biocombustíveis com vistas a cumprir as metas de redução de GEEs assumidas pelo país no Acordo de Paris (ANP, 2021).

O PNPB, além de estabelecer a obrigatoriedade de um percentual de biodiesel na composição do diesel comercializado, possui uma política de inclusão com incentivos a participação de famílias praticantes da agricultura familiar na cadeia produtiva do biodiesel (BRASIL, 2021).

De acordo com o IBGE, no último censo agropecuário no ano de 2017, $77 \%$ dos estabelecimentos agrícolas existentes no país foram classificados como agricultura familiar, sendo a base da economia de $90 \%$ dos municípios com até 20 mil habitantes. De todo o pessoal ocupado com a agricultura no país (cerca de 10,1 milhões de pessoas), 67\% são de agricultura familiar, produzindo o equivalente a $23 \%$ de toda a produção agropecuária brasileira (IBGE, 2017).

A inserção da agricultura familiar em um programa energético constituiu um modelo inovador: diferentemente de outros países, o desenvolvimento social foi pautado como um dos alicerces do programa, tendo sido criado o Selo Biocombustível Social (SBS) ${ }^{1}$, como estratégia para auxiliar os pequenos produtores em capacitação, acesso ao mercado e escoamento da produção. Produtores de biodiesel que adquirem matéria-prima proveniente da agricultora familiar e cumprem outros requisitos legais, adquirem o SBSe, com isso, recebem benefícios fiscais e privilégios para comercializar o biodiesel nos leilões da ANP (EPE, 2020).

Esse mecanismo de incentivos gera uma importante interação entre as famílias dos agricultores e as empresas do setor. A maioria desses agricultores é de pequenos produtores que inicialmente praticavam uma agricultura informal e precária, sem utilizar inovações tecnológicas ou organização em sua produção (VILLANUEVA, 2019) e, através da capacitação, há a elevação do padrão de produção agrícola, tanto na produtividade quanto no volume e qualidade, o que gera o aumento da renda dessas famílias, promovendo seu desenvolvimento econômico e social.

\footnotetext{
${ }^{1}$ Inicialmente o SBS foi denominado de Selo Combustível Social (SCS), porém passou a ser chamado de SeloBiocombustível Social (SBS).
} 
Erradicar a pobreza é o principal foco da Agenda 2030 da Organização das Nações Unidas que pretende engajar a comunidade internacional por meio de metas nos 17 Objetivos do Desenvolvimento Sustentável (ODS). A estratégia do PNPB está relacionada com vários destes ODS, como erradicação da fome, melhoria na qualidade de vida, aumento de renda, redução de desigualdade social, desenvolvimento de uma agricultura mais produtiva e sustentável, além da produção de um biocombustível renovável, que contribui para a mitigação de efeitos das mudanças climáticas (BRASIL, 2020).

O presente trabalho tem como objetivos: relacionar a estratégia do PNPB de inserção da agricultura familiar na cadeia produtiva do biodiesel aos ODS da Agenda 2030 e ao direito constitucional ao desenvolvimento das populações; avaliar a efetividade da política pública de inserção da agricultura familiar na cadeia produtiva do biodiesel atravésdos dados da participação de produtores detentores do SBS nos leilões da ANP; avaliar, a partir do percentual de participação do biodiesel na matriz energética brasileiraa partir do período em que foi instituído o PNPB, a eficácia dessa política pública na inserção do biodiesel na composição da matriz energética brasileira de transportes. Foi utilizada a metodologia de pesquisa bibliográfica em artigos publicados em periódicos e sites especializados bem como análise de dados disponibilizados nos sites oficiais do Governo.

A hipótese central do trabalho é de que o PNPB e as suas estratégias de aumentar a participação da agricultura familiar na cadeia produtiva do biodiesel é uma política pública eficaz que resultou no aumento efetivo da participação dessas famílias no ciclo de produção do biocombustível possibilitando, por meio da capacitação desses agricultores, da melhoria na qualidade de vida dessas famílias através do aumento da sua renda, trazendo eficácia ao direito ao desenvolvimento de diversas famílias e regiões mais pobres do país; além disso, espera-se que o programa federal seja capaz de propiciar o aumento da participação do biodiesel na matriz energética nacional considerando-se a data de sua implementação.

\section{OS BIOCOMBUSTÍVEIS NA MATRIZ ENERGÉTICA BRASILEIRA}

Apesar de a produção de álcool combustível brasileira já possuir uma expressiva e consolidada participação no mercado mundial (UDOP,2020), outros biocombustíveis têm um grande potencial de crescimento considerando-se o grande espaço agriculturável do país e as políticas de incentivos do Governo Federal como o RenovaBio e o Programa Nacional de Produção e Uso do Biodiesel (PNPB). 
O uso das energias limpas no Brasil é bastante relevante se comparado com outros países. De acordo com o Ministério de Minas e Energia (2021), no ano de 2010 mais de 40\% da matriz energética brasileira era composta por energias renováveis, enquanto que a média mundial era de $12,7 \%$. No ano de 2021 , as energias renováveis são responsáveis por $46,1 \%$ da matriz energética brasileira, conforme demonstrado na figura abaixo:

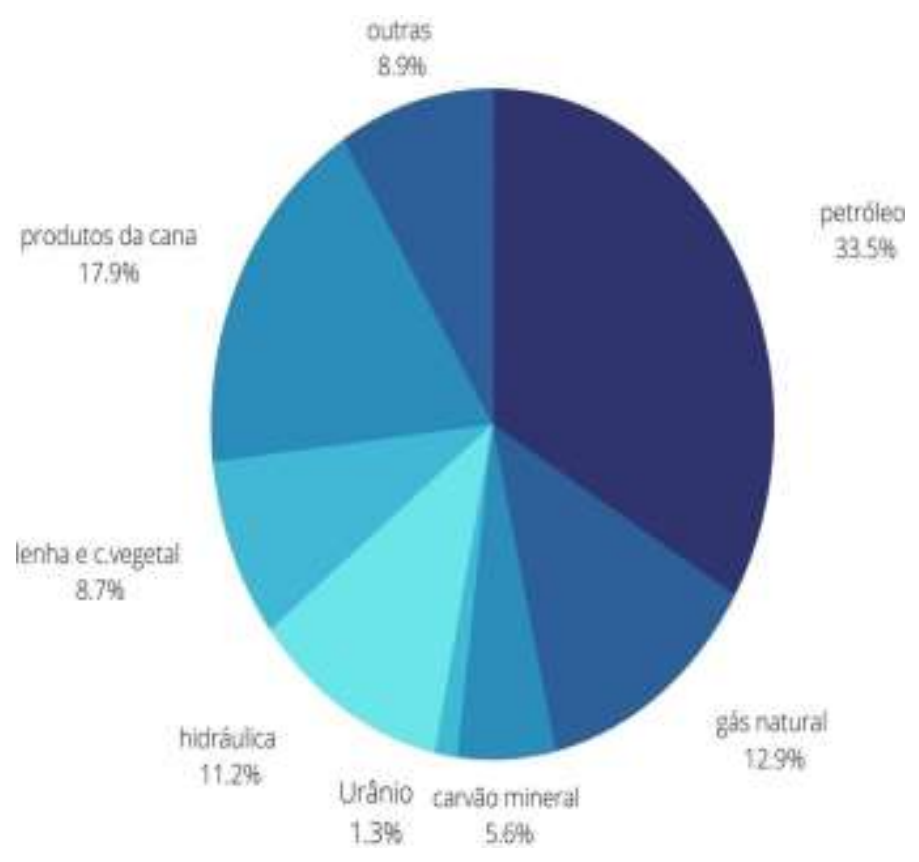

A diversidade da matriz energética brasileira é um dos atributos que contribuem para a segurança energética do país. A maior parte da energia gerada no Brasil é produto da soma das energias da biomassa e das usinas hidrelétricas.

Em 2020, a matriz do setor de transportes foi composta por $26 \%$ de biocombustíveis, etanol anidro e hidratado e biodiesel produzidos no Brasil e a inserção de biocombustíveis nessa matriz se deu a partir da obrigatoriedade de misturas de biocombustíveis nos combustíveis fósseis.

\subsection{A PRODUÇÃO DE BIODIESEL NO BRASIL}

O biodiesel é um biocombustível obtido a partir da conversão de óleos vegetais extraídos de oleaginosas como soja, palma, girassol, da gordura animal e de outras matériasprimas, utilizado como substituto ao óleo diesel de origem mineral (diesel A). 
A Lei 11.097/2005 estabeleceu uma definição ampla para o biodiesel, conceituandoo como sendo qualquer combustível derivado da biomassa renovável para uso em motores do ciclo diesel ${ }^{2}$. Com o surgimento de novas tecnologias, foi necessária uma regulamentação que incorporasse essa definição mais ampla, e a Resolução no 45/2014 da ANP tornou possível a adição de outros combustíveis renováveis provenientes da biomassa ao diesel fóssil para compor a mistura do diesel $\mathrm{B}^{3}$.

Dentre as várias fontes disponíveis para a produção de biodiesel, os óleos vegetais se destacam não só pela adequação de suas propriedades, mas por representarem forte apoio à agricultura familiar, criando condições de desenvolvimento em regiões carentes, valorizando potencialidades regionais e sendo uma potencial solução para problemas socioeconômicos sendo o mercado de soja um importante agronegócio brasileiro (SALLET; ALVIM, 2011).

De acordo com dados da Associação Brasileira das Indústrias de Óleos Vegetais ABIOVE - o óleo de soja representa a principal matéria-prima para a produção de biodiesel, havendo um equilíbrio na sua produção média anual (aproximadamente $70 \%$ da produção) enquanto as gorduras animais são responsáveis por cerca de $15 \%$ da produção de biocombustíveis. O gráfico abaixo mostra a produção de biodiesel por matéria-prima no Brasil entre os anos de 2008 e 2021.

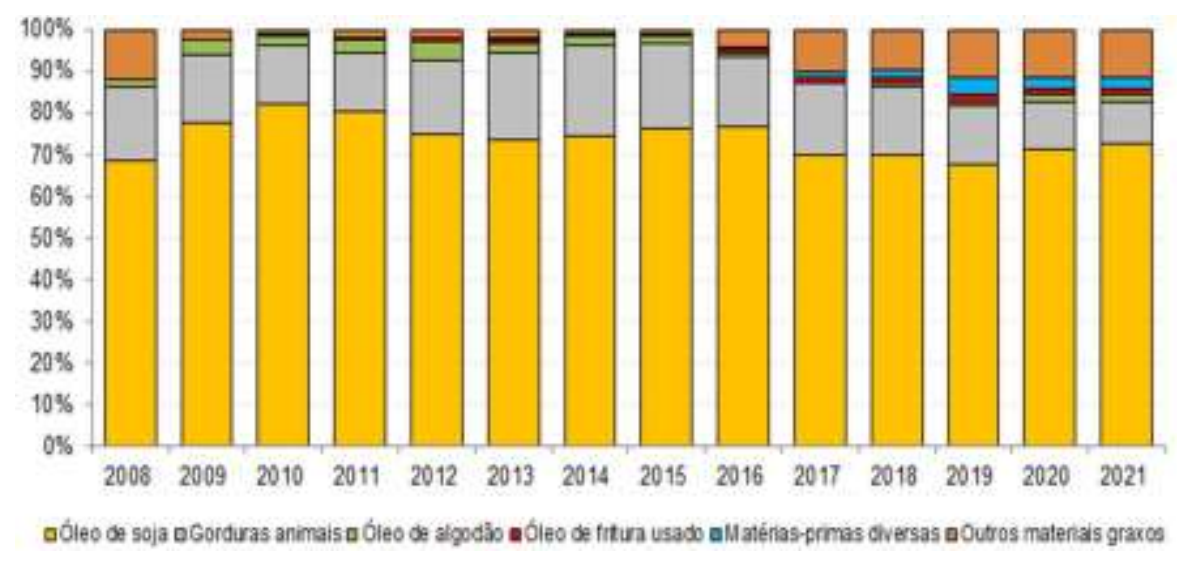

(fonte: $\mathrm{ANP} / \mathrm{ABIOVE}$ )

\begin{abstract}
${ }^{2}$ Lei 11.097/2005. Art. 4, XXV. "Biodiesel: biocombustível derivado de biomassa renovável para uso em motores acombustão interna com ignição por compressão ou, conforme regulamento, para geração de outro tipo de energia, que possa substituir parcial ou totalmente combustíveis de origem fóssil.".

${ }^{3} \mathrm{O}$ diesel de uso rodoviário é classificado em óleo diesel A e óleo diesel B, sendo o diesel A produzido a partirdo refino do petróleo sem adição de biodiesel e o diesel B possui adição de biodiesel em sua composição, no percentual mínimo obrigatório estabelecido pelo CNPE.
\end{abstract}


O Programa Brasileiro de Produção e Uso de Biodiesel (PNPB) se iniciou em 2005 com a mistura voluntária de 2\% (B2) de biodiesel no diesel comercial (diesel B), tornando-se obrigatória a partir de 2008 e devendo chegar em 15\% em 2023 de acordo com e Resolução n ${ }^{\circ}$ 16/2018 do Conselho Nacional de Política Energética (CNPE), que estabeleceu diretrizes e autorizou a ANP a fixar o percentual obrigatório de biodiesel ao óleo diesel vendido ao consumidor final. De acordo com a citada Resolução (MME, 2018), no ano de 2021 o percentual obrigatório deveria ser de 13\% (B13).

Desde 2007, a comercialização do biodiesel é feita através de leilões públicos organizados pela ANP, observando as diretrizes gerais estabelecidas pelo CNPE e pelo Ministério de Minas e Energia (MME) ${ }^{4}$. Os leilões visam a aquisição de biodiesel pelas refinarias e importadores de óleo diesel para atendimento ao percentual mínimo de biodiesel que deve ser adicionado ao diesel fóssil.

De acordo com a Análise de Conjuntura dos Biocombustíveis (2020), até o final do ano de 2020 foram realizados 77 leilões. Porém a partir do leilão 73 houve um aumento significativo dos preços do biodiesel, justificado por, entre outros fatores, a elevação do preço das commodities (soja e seus derivados) e pela desvalorização do real e o aumento da produção de soja para exportação, estimulada pelos altos preços do mercado internacional. Tais fatores, de cordo com o Ministério, poderiam levar a um aumento excessivo do preço do diesel com reflexos no transporte de cargas do país e na economia, de acordo com a Forbes $(2021)^{5}$. Além disso, o preço do diesel na refinaria em 2020 apresentou queda em relação ao ano de 2019, refletindo o impacto da oferta e demanda de petróleo. Tais fatores levaram a uma discrepância entre os valores do biodiesel e do diesel, chegando a, no Leilão 77, o preço do biodiesel superar em duas vezes o do diesel nas refinarias, sem o ICMS, segundo dados da Análise de Conjuntura de Biocombustíveis (2020).

Para garantir o abastecimento do mercado interno, a ANP determinou três medidas temporárias de redução dos percentuais de adição de biodiesel ao diesel ao longo de 2020 para

${ }^{4}$ São realizados 6 leilões por ano e cada um dos leilões visa ao atendimento bimestral de biodiesel para a mistura ao diesel A, para cumprimento do percentual mínimo obrigatório para a formação do diesel B. 
garantir o abastecimento do mercado interno. No ano de 2021, essas ações também foram necessárias, quando o percentual foi reduzido para $10 \%$, juntamente com outros mecanismos de mercado como a redução à zero da alíquota do imposto de importação da soja e seus derivados farelo e grão; bem como a aprovação da Resolução CNPE nº 09/2020 pela qual se declarou o interesse da Política Energética Nacional a permissão, pela ANP, da utilização de matéria-prima importada para a produção de biodiesel nos editais dos leilões públicos para a comercialização do biodiesel a ser incorporado ao diesel.

Outro mecanismo implantado para alavancar a produção de biodiesel de forma a tornálo competitivo relativamente ao óleo diesel foi a introdução do biodiesel autorizativo por meio da Resolução CNPE no 03 (2015), que definiu diretrizes para autorizar a comercialização e o uso voluntário de biodiesel em quantidades superiores aos percentuais de adição exigidos obrigatoriamente. A adoção desse mecanismo de biodiesel autorizativo visa promover principalmente as regiões distantes de refinarias e com abundância de capacidade produtiva, segundo a Análise de Conjuntura dos Biocombustíveis (2020). Esse biodiesel também é comercializado nos leilões da ANP em uma etapa posterior à comercialização do volume obrigatório, enquanto biodiesel obtido através de misturas distintas das previstas na legislação podem ser comercializados diretamente pelos produtores, desde que haja autorização da ANP.

No ano de 2020 foram ofertados aproximadamente $86 \mathrm{mil} \mathrm{m}^{3}$ de biodiesel autorizativo, porém apenas $800 \mathrm{~m}^{3}$ foram arrematados, de acordo com a ANP (2020) - 0,9\% do total - tendo sido os elevados valores do biodiesel um dos fatores que contribuíram para a baixa comercialização nesse tipo de certame. No $72^{\circ}$ Leilão foram arrematados $400 \mathrm{~m}^{3}$ de biodiesel autorizativo sem que nenhum $\mathrm{m}^{3}$ tenha sido arrematado nos leilões posteriores.

Porém, a partir de janeiro de 2022, a sistemática de comercialização de biodiesel no mercado nacional irá se modificar e não haverá mais leilões de biodiesel: a comercialização se dará diretamente entre o produtor e o consumidor. Este modelo torna mais acessível a comercialização de biodiesel quando comparada à aquisição através de leilões, além de promover uma maior eficiência de mercado, pois permite que os compradores e vendedores negociem as opções mais vantajosas.

De acordo com a Nota Técnica Conjunta no 10/2021/ANP (2021), que propõe o novo modelo de comercialização do biodiesel, tal mudança é necessária para abarcar as necessidades advindas do crescimento do mercado de biocombustíveis nacional, sendo formado por um grande número de agentes que produzem, fornecem e consomem o biodiesel e com potencial 
de crescimento dada a obrigatoriedade de mistura mínima ao diesel A. Assim, não sendo observadas falhas de mercado, não há necessidade de mecanismos regulatórios muito rigorosos, em favor dos princípios constitucionais do livre mercado e da livre concorrência. Se as próprias políticas energéticas estão pautadas em, entre outros, por diretrizes como a transição para a nova configuração do mercado estabelecidas através da Res. CNPE no 15/2017, ${ }^{6}$ não há óbices para a introdução de mecanismos que promovam mais eficiência na comercialização do biodiesel e um estímulo a mais para a sua produção.

O mecanismo proposto consiste na previsão de que produtores de biodiesel e distribuidores negociem livremente volumes e preços de produto para atenderem uma meta mínima de contratação prévia estipulada pela ANP, de forma a cumprirem a obrigação do percentual de mistura do biodiesel ao diesel A e, após um período, ambos apresentem à ANP as informações da operação para avaliação do cumprimento da meta mínima volumétrica. $\mathrm{O}$ restante do volume a ser negociado, acima da meta mínima de contratação estabelecida, poderá ser negociado por meio de qualquer sistemática.

Ainda segundo a nota técnica da ANP, com o objetivo de não desestimular os pequenos produtores, que, embora não comprometam o abastecimento do mercado levando-se em conta a sua participação, são importantes na contestação de mercado, estimulam a competitividade e, em último caso favorecem o consumidor. Assim, foi sugerida uma linha de corte onde estariam obrigados a contratar e, consequentemente cumprir metas, apenas aqueles produtores que representarem participação de mercado igual ou superior a $3 \%$ do volume total de biodiesel comercializado no ano anterior em todo o país; bem como os distribuidores de combustíveis líquidos que representarem percentual igual ou superior a $5 \%$ do volume de diesel $\mathrm{B}$ comercializado em pelo menos uma unidade da federação, descontando-se o volume de diesel B já adquirido por cada distribuidor de outro distribuidor congênere ${ }^{7}$.

De acordo com a Análise de Conjuntura dos Biocombustíveis para o ano de 2020 publicado pela Empresa de Pesquisa Energética (EPE), embora a pandemia de covid-19 tenha

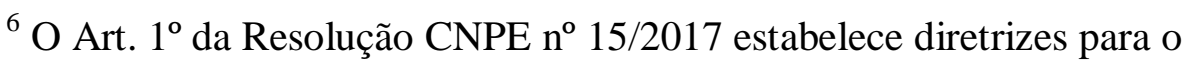
desenvolvimento do mercado de combustíveis, demais derivados do petróleo e biocombustíveis, com o objetivo de embasar a posição de medidas que contribuam para a garantia do abastecimento nacional e dá outras providências.

${ }^{7}$ De acordo com a NT, tomando como base os dados de comercialização de diesel B para o ano de 2020, o critério de corte de $5 \%$ resultou no total de 26 distribuidoras representado $86 \%$ de todo o diesel B comercializado no mercado interno em 2020 e, com relação aos produtores, considerando-se os dados de 2020, o corte de $3 \%$ importa no total de 13 produtores obrigados ao cumprimento de metas, representado $76 \%$ do total de vendas de biodiesel por produtores para as distribuidoras em 2020, além de somarem $31 \%$ da capacidade instalada de produção.
} 
impactado a demanda de combustíveis, inclusive os biocombustíveis, foram produzidos 6,4 bilhões de litros, considerado um recorde histórico, segundo a Análise de Conjuntura de Biocombustíveis (2020). Em relação ao biodiesel, foram consumidos 6,6 bilhões de litros no Brasil, representando um aumento de 10\% em relação a 2019.

O gráfico abaixo obtido a partir da ANP (2020), mostra a produção nacional de biodiesel em $\mathrm{m}^{3}$, mensalmente, entre os anos de 2005 e 2020.

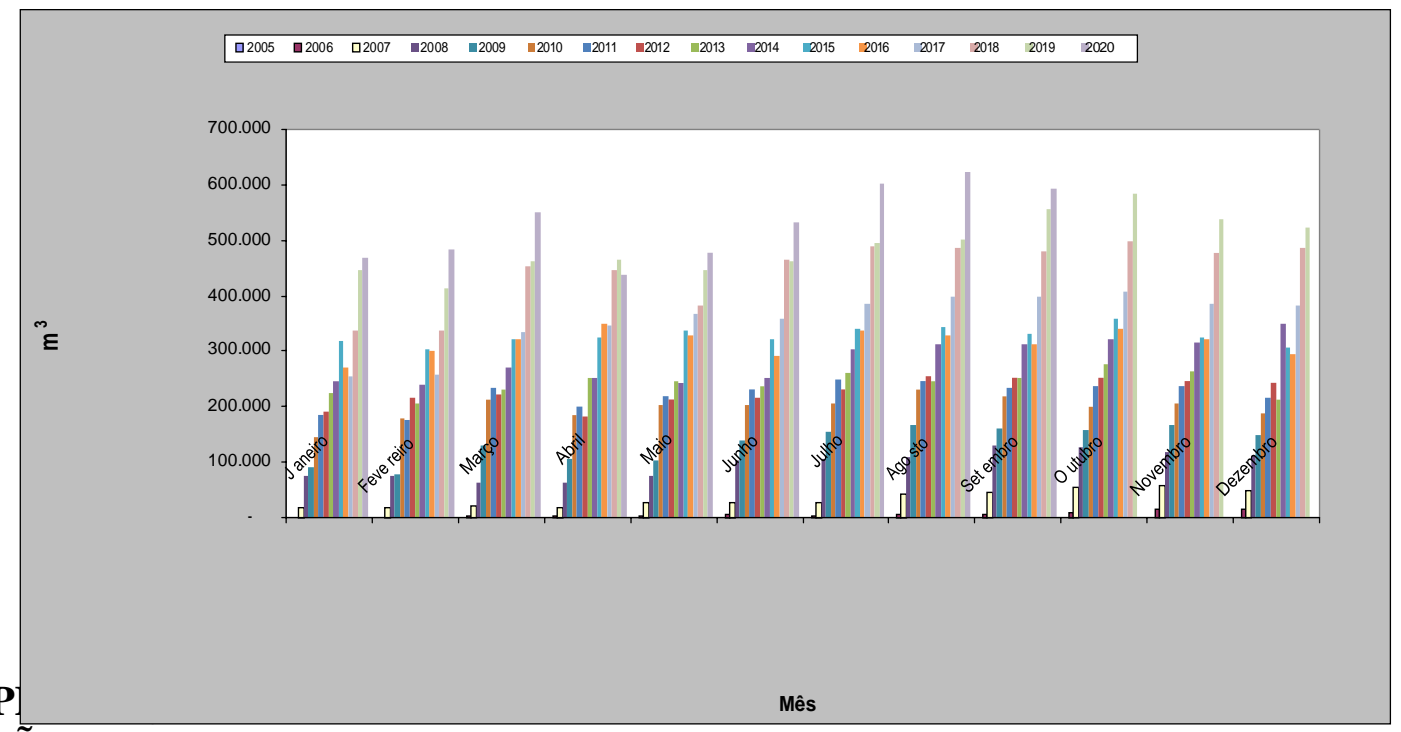

\subsection{A P \\ RELAÇÃO COM O DIREITO AO DESENVOLVIMENTO E A AGENDA 2030.}

O PNPB se baseou em três pilares: social, ambiental e econômico. Enquanto o enfoque ambiental se dá pela redução da emissão de poluentes e gases de efeito estufa; o econômico se traduz na substituição da necessidade de importação de óleo diesel, considerando-se quea produção brasileira não é suficiente para atender a demanda; e o enfoque social se dá através da inclusão social e o desenvolvimento regional através da geração de emprego e renda com a produção de biocombustíveis ${ }^{8}$.

Para estimular esse processo, o programa elaborou o Selo Biocombustível Social (SBS), uma série de medidas para promover e facilitar a inclusão da produção de biodiesel por famílias que praticam a agricultura familiar. De acordo com o Ministério de Minas e Energia, o cultivo da matéria-prima para a elaboração do biodiesel e a sua produção industrial - a cadeia produtiva do biodiesel- tem grande potencial de geração de empregos, sendo uma forma de inclusão social, especialmente com relação ao amplo potencial produtivo da agricultura

\footnotetext{
${ }^{8}$ A agricultura familiar representa uma importante fonte de renda, ocupação e mão de obra no meio rural.
} 
familiar. Em áreas extremamente pobres do Brasil onde não existem muitas oportunidades de desenvolvimento como o Semi-árido do Nordeste e a região Norte ${ }^{9}$, a inclusão social oportunizada pela inclusão dessas famílias é ainda mais premente.

De acordo com o IBGE, no último censo agropecuário realizado no ano de $2017^{10}$, $77 \%$ dos estabelecimentos agrícolas existentes no país foram classificados como agricultura familiar, sendo a base da economia de $90 \%$ dos municípios com até 20 mil habitantes. De todo o pessoal ocupado com a agricultura familiar no país (cerca de 10, 1 milhões de pessoas), 67\% são de agricultura familiar, produzindo o equivalente a $23 \%$ de toda a produção agropecuária brasileira (IBGE, 2017).

Para obter o SBS, os produtores de biodiesel, além de comprar matéria-prima proveniente da agricultura familiar, devem cumprir certos requisitos como assegurar preço mínimo, comprar um percentual mínimo de insumos, prestar assistência técnica bem como capacitar esses agricultores e fechar contratos prévios de compra e venda direta com os agricultores ou através de cooperativas. Ao obter o selo, que é concedido pelo Ministério da Agricultura (MAPA), os produtores têm direito a alguns benefícios tributários ${ }^{11}$, além do acesso diferenciado aos leilões da ANP para a comercialização de biodiesel a ser misturado obrigatoriamente ao diesel fóssil.

As famílias que participam do PNPB (agricultores) também possuem obrigações legais como estar enquadrado no Programa Nacional de Fortalecimento da Agricultura Familiar (Pronaf) e cadastrados no CAR (Cadastro Ambiental Rural) para poderem ser beneficiadas. Os agricultores familiares devem ser capacitados para a produção de oleaginosas de forma compatível com a segurança alimentar da família e com o processo de geração de renda de

${ }^{9}$ De acordo com o Ministério, no Semi-Árido a renda anual de uma família a partir do cultivo de cinco hectares de mamona que forneça uma produção média entre 700 e $12 \mathrm{mil} \mathrm{kg} / \mathrm{hectare}$ pode variar entre 2,5 e 3,5 mil reais. Além disso, a área pode ser consorciada com outras culturas agrícolas como o milho e o feijão, o que é importante para o abastecimento do mercado de alimentos do país, já que a agricultura familiar é importante para esse setor. ${ }^{11}$ Os benefícios fiscais aumentam conforme a diversificação de matéria-prima e o seu local de origem, sendomaiores quando esse insumo for diferente de soja e milho e/ou proveniente da região Nordeste e Semiárido. 
forma que a agricultura familiar seja inserida na cadeia produtiva do biodiesel e a propriedade seja sustentável.

Desde o início do programa, em 2005, até o final de 2020, foram produzidos 47 bilhões de biodiesel no Brasil e destes, $80 \%$, no mínimo, foi proveniente de empresas detentoras do Selo Biocombustível Social.

A tabela abaixo aponta o número de famílias inseridas no arranjo do Selo Biocombustível Social no Brasil, por ano, desde o início do Programa, até o ano de 2020 (COER/MAPA, 2021).

\begin{tabular}{|c|c|}
\hline 2008 & 28.656 \\
\hline 2009 & 51.047 \\
\hline 2010 & 100.371 \\
\hline 2011 & 104.295 \\
\hline 2012 & 92.673 \\
\hline 2013 & 83.754 \\
\hline 2014 & 73.479 \\
\hline 2015 & 72.485 \\
\hline 2016 & 70.255 \\
\hline 2017 & 59.909 \\
\hline 2018 & 61.983 \\
\hline 2019 & 59.265 \\
\hline 2020 & 74.244 \\
\hline
\end{tabular}

De acordo com os dados disponibilizados no Portal Brasileiro de Dados Abertos (2018), no ano de 2008, o volume de matéria-prima adquirida da agricultura familiar nos arranjos do Selo Biocombustível Social era de 361,57 mil toneladas, crescendo para 3.810. mil em 2018.

Ao inserir os trabalhadores na cadeia produtiva do biodiesel por meio do SBS, o PNPB oportunizou a essas famílias o direito ao desenvolvimento ${ }^{12}$, no sentido de que a efetiva proteção ao desenvolvimento das pessoas como seres humanos bem como a proteção de direitos

${ }^{12}$ A ideia do Direito ao desenvolvimento surgiu no âmbito da Organização das Nações Unidas e, através da Declaração Sobre o Direito ao Desenvolvimento de 1986, entendeu-se ser este um direito humano inalienável por meio do qual todas as pessoas humanas estão habilitadas a participar do desenvolvimento econômico, social, cultural e político da humanidade, dele usufruir e a ele contribuir. 
econômicos e culturais demanda não apenas políticas universalistas, mas também políticas específicas em favor de determinados grupos de vulneráveis (PIOVESAN, 2002).

De acordo com o Ministério da Agricultura, a agricultura familiar pode fornecer outras matérias-primas diferentes das que serão utilizadas na produção do biodiesel e estas também serão contabilizadas no processo de obtenção do SBS pelas empresas, numa forma de valorizar as culturas regionais e fomentar a participação de regiões com pouca representatividade no mercado. Além disso, a assistência técnica prestada pelos produtores de biodiesel aos agricultores familiares pode ser estendida a essas outras culturas e atividades, segundo o Ministério da Agricultura (2021).

Os dados apresentados na Análise de Conjuntura dos Biocombustíveis (2020), elaborado pela EPE demonstram o sucesso do SBS na renda média das famílias participantes: a renda média anual passou de $\mathrm{R} \$ 18,5$ mil para $\mathrm{R} \$ 70,8$ mil em 2016 , estabilizando-se em torno de R $\$ 80$ mil, considerando-se os dados até dez/2020. Os números correspondem à renda obtida com a comercialização da matéria-prima para a produção do biodiesel, ainda podendo as famílias obterem fontes adicionais provenientes de outras atividades.

Esses trabalhadores tiveram uma notável melhoria da qualidade de vida e renda, reduzindo as desigualdades sociais, além do aprimoramento técnico e desenvolvimento de uma agricultura mais produtiva e sustentável, tornando-se capazes de desenvolver suas capacidades, no sentido de desenvolvimento de Amartya $\operatorname{Sen}^{13}$, para quem a liberdade é a principal fonte de desenvolvimento humano e social e, para adquiri-la, é necessário remover a pobreza e a carência de oportunidades (SEN, 2018).

Inseridos no PNPB, os agricultores familiares mantêm parceria com o programa que oferece alimentação escolar e ações de educação alimentar e nutricional a estudantes da educação básica pública, o Programa Nacional de Alimentação Escolar (PNAE) do Governo Federal, o que contribui para o alcance do ODS da Agenda 2030 que contempla uma educação de qualidade, além de, como anteriormente ressaltado, fortalecer o desenvolvimento das capacidades desses cidadãos.

${ }^{13}$ Para Amartya Sen (2018), a economia é uma parte do direito ao desenvolvimento. O desenvolvimento é o resultado das liberdades que as pessoas podem desfrutar e milhares de pessoas estão privadas de desfrutar essas liberdades devido a fatores como desnutrição, falta de oportunidades, de emprego adequadamente remunerado efalta de educação. 
A adoção de fontes renováveis para a produção de biocombustíveis, portanto, aumenta a renovabilidade de matriz energética nacional e impulsiona o Brasil a atender aos seus compromissos internacionais, convergindo com o ODS de ações contra a mudança global do clima, além de promover o bem-estar e do desenvolvimento sustentável das sociedades. As atividades realizadas por essa agricultura familiar do PNPB tangenciam diversos ODS da Agenda 2030. (BRASIL, 2020).

\section{CONCLUSÃO}

O Programa Nacional de Produção e Uso de Biodiesel tem como uma de suas bases o incentivo à agricultura familiar, por meio do Selo de Biocombustível Social, ferramenta de inclusão social e geração de emprego e renda, inserindo as famílias praticantes da agricultura familiar na cadeia produtiva do biodiesel. No ano de 2008, quando o PNPB foi criado, 28.565 famílias foram inseridas no SBS e no ano de 2020, o número de famílias participantes era de 74.244 - aproximadamente 2,5 vezes a mais. Assim, podemos concluir que O PNPB é importante política pública de inserção da agricultura familiar na dinâmica formal da economia - de acordo com o Balanço Energético, no ano de 2020, 99,1\% do biodiesel vendido nos leilões foi oriundo de empresas detentoras do SBS.

Esse arranjo do PNPB, apesar de ter sido implementado no ano de 2008, possui objetivos bastante atuais já que, além de promover o desenvolvimento econômico e das capacidades desses agricultores, se aproxima dos Objetivos de Desenvolvimento Sustentável da Agenda 2030, como erradicação da fome, melhoria na qualidade de vida, aumento de renda, redução de desigualdade social, desenvolvimento de uma agricultura mais produtiva e sustentável, além do que, as matérias-primas produzidas contribuem para a produção de uma energia limpa, promovem a inserção de energias renováveis na matriz energética nacional, e auxilia o cumprimento dos objetivos de diminuição de GEE e, consequentemente, nas ações de mitigação de mudanças climáticas.

Entretanto, problemas de mercado como a dependência da soja como principal matéria-prima da produção do biodiesel, a desvalorização do real resultando na alta do preço do biodiesel na sua comercialização em comparação ao diesel fóssil tendo, como consequência, políticas de redução da obrigatoriedade do percentual de sua adição ao diesel B, podem gerar uma perda na eficiência dessa inclusão e os leilões de biodiesel já estão refletindo a diminuição na demanda pelo biocombustível o que pode gerar, em escala, da perda de vários postos de 
trabalho na cadeia produtiva e a perda de renda de diversas famílias de agricultores que puderam se beneficiar dessa política.

Assim, é necessário um acompanhamento tanto do Governo como dos órgãos que regulam e que são responsáveis pelo acompanhamento da política de inserção da agricultura familiar na cadeia produtiva do biodiesel, a fim de se traçar uma estratégia para que não haja um retrocesso no Programa que, como demonstrado, é importante para diversos setores da sociedade.

\section{REFERÊNCIAS BIBLIOGRÁFICAS}

ABIOVE. Associação Brasileira das Indústrias de Óleos Vegetais. Biodiesel: Produção por tipo de matéria-prima. Disponível em: https://abiove.org.br/estatisticas/biodiesel-producaopor-tipo-de-materia-prima/. Acesso em 15 set. 2021.

BRASIL. Agência Nacional de Petróleo, Gás e Biocombustíveis. Disponível em:

<https://www.gov.br/anp/pt-br/assuntos/renovabio>. Acesso em: 15 set. 2021.

BRASIL. Agência Nacional de Petróleo, Gás e Biocombustíveis. Nota Técnica Conjunta $n^{o}$ 10/2021/ANP. Disponível em: <https://www.gov.br/anp/pt-br/assuntos/producao-efornecimento-de-biocombustiveis/biodiesel/ntconj2021.pdf.> Acesso em 17 set. 2021.

BRASIL. Diário Oficial da União. Resolução CNPE $n^{\circ}$ 09/2020. Estabelece como de interesse da Política Energética Nacional a utilização de matéria-prima importada para a produção de biodiesel. Disponível em: <https://www.in.gov.br/en/web/dou/-/despacho-dopresidente-da-republica-288976231>. Acesso em 19 set. 2021.

BRASIL. Empresa de Pesquisa Energética. Análise de Conjuntura dos Biocombustíveis 2020. Disponível em: https://www.epe.gov.br/sites-pt/publicacoes-dadosabertos/publicacoes/Publicacoes Arquivos/publicacao-615/NT-EPE-DPG-SDB-202103 Analise de Conjuntura dos Biocombustiveis ano 2020.pdf. Acesso em 20/09/2021.

BRASIL. Resolução CNPE $n^{\circ} 03 / 2015$. Autoriza e define diretrizes para comercialização e uso voluntário de biodiesel. Disponível em:

<https://www.legisweb.com.br/legislacao/?id=304592 >. Acesso em 17 set. 2021 
BRASIL. Lei $n^{o} 11.097 / 2005$. Dispões sobre a introdução do biodiesel na matriz energética brasileira. Disponível em:< http://www.planalto.gov.br/ccivil_03/_ato2004-

2006/2005/lei/111097.htm> Acesso em 18 set. 2021.

BRASIL. Ministério da Agricultura, Pecuária e Abastecimento. Programa Nacional de Produção e Uso do Biodiesel (PNPB). Disponível em:< https://www.gov.br/agricultura/ptbr/assuntos/agricultura-familiar/biodiesel/programa-nacional-de-producao-e-uso-do-biodieselpnpb> Acesso em: 20 set. 2021.

BRASIL. Ministério da Agricultura, Pecuária e Abastecimento. Selo Biocombustível Social aumenta produtividade e renda dos participantes. Disponível em: $<$ https://www.gov.br/ptbr/noticias/agricultura-e-pecuaria/2021/01/selo-biocombustivel-social-aumentaprodutividade-e-renda-de-participantes>. Acesso em 17 set. 2021.

BRASIL. Ministério de Minas e Energia. Conselho Nacional de Pesquisa Energética. Resolução $n^{o}$ 16/2018. Dispõe sobre a evolução da adição obrigatória de biodiesel ao óleo $\mathrm{d}$ /iesel vendido ao consumidor final, em qualquer parte do território nacional. Disponível em: $<$ http://antigo.mme.gov.br/documents/36074/265770/Resolucao_16_CNPE_29-1018.pdf/03661cf7-007d-eb99-10b4-61ee59c30941> Acesso em: 17 set. 2021.

BRASIL. Ministério de Minas e Energia. Boletim Mensal de Energia - Mês de referência: junho/2021. Disponível em:< https://www.udop.com.br/boletins-

arquivos/81/2021/mme_boletim_mensal_energia_jun21_publicado_27ago21.pdf $>$ Acesso em: 17 set. 2021.

BRASIL. Portal Brasileiro de Dados Abertos. Volume e Valor da Matéria-Prima Adquirida da Agricultura Familiar. Disponível em: <https://dados.gov.br/dataset/pnpbvolume-valor-da-materia-prima-adquirida-da-af> Acesso em 21 set. 2021.

DISSANAYAKE, S.; MAHADEVAN, R.; ASAFU-ADJAYE, J. Evaluating the efficiency of carbon emissions policies in a large emitting developing country. Energy Policy. V.136, january 2020.

FORBES. Governo fixa mistura obrigatória em $12 \%$ para $81^{\circ}$ Leilão de Biodiesel. Disponível em:< https://forbes.com.br/forbes-money/2021/07/governo-fixa-misturaobrigatoria-em-12-para-81o-leilao-de-biodiesel/.> Acesso em 17 set. 2021. 
IBGE. Censo Agro 2017. Disponível em:

<https://censos.ibge.gov.br/agro/2017/templates/censo agro/resultadosagro/index.html> Acesso em 18 set. 2021.

IPCC. Intergovernmental Panel os Climate Change. Global Warmin of $1,5^{\circ} \mathrm{C}$. Disponível em: 〈https://www.ipcc.ch/sr15/>. Acesso em: 15 set. 2021.

PIOVESAN. Flávia Cristina. Direito ao Desenvolvimento. II Colóquio Internacional de Direitos Humanos. São Paulo, Brasil, 2002. Disponível em: 17/http://www.dhnet.org.br/direitos/sip/onu/spovos/lex170a.htm. Acesso em: 17 set. 2021.

SALLET, C.; ALVIM, A.M. Biocombustíveis: uma análise da evolução do biodiesel no Brasil. Economia \& Tecnologia. Ano 07, vol. 25. Abr/Jun 2011.

SEN, AMARTYA. Desenvolvimento como Liberdade. Trad. Laura Teixeira Motta. Ed. Companhia das Letras: São Paulo, 2018.

UDOP. União Nacional da Bioenergia. Dados de mercado: produção nacional de biodiesel. Disponível em:< https://www.udop.com.br/producao-brasileira $>$ Acesso em: 20 set. 2021.

UDOP. União Nacional da Bioenergia. A utilização de Óleo Vegetal Refinado como Combustível - Aspectos Legais, Técnicos, Econômicos, Ambientais e Tributários. Textospara Discussão 73. Disponível em: $<$ https://www.udop.com.br/producao-brasileiraarquivos/15/estudo_completo_biodiesel.pdf $>$ Acesso em: 19 set. 2021.

VILLANUEVA, Bernardo de Almeida. Selo combustível e a inclusão da agricultura familiar na cadeia produtiva do biodiesel. 2019. 134 f. Dissertação (Mestrado em Planejamento e Governança Pública) - Universidade Federal Tecnológica do Paraná, Curitiba, 2019. 